\title{
Assessment of Axial Flux Motor Technology for Hybrid Powertrain Integration
}

\author{
Michael U Lampérth, Adam C Malloy, Adrian Mlot, Mark Cordner \\ GKN EVO eDrive Systems Ltd, Unit 14, Woking Business Park, Woking GU21 5JY, U.K. \\ Michael.Lamperth@gkn-evo.com
}

\begin{abstract}
Axial flux (AF) motors and generators have been used in niche automotive applications for many years. Given their disk like shape they offer distinct advantages for integration into hybrid powertrains where available length is limited. An overview of axial machine topologies is given and the design and performance laws that govern the sizing of axial flux permanent magnet machines are presented. Based on the analytical laws described it is shown that an axial machine can achieve significantly more torque than a size comparable radial machine. 3D finite element analysis is used to fine-tune designs and to investigate loss mechanisms.

A P2 hybrid module case study is used to show the benefits and challenges of the axial topology when compared to the radial one. The cooling system of the machine is presented in order to show how the integration of coolant passages could be achieved. The possibility of introducing heat barriers into a hybrid powertrain, decoupling the hybrid module from the rest of the powertrain, is also presented. The predicted performance of the machine is presented and compared to the initial test results.
\end{abstract}

Keywords: Axial Flux, Hybrid Module, P2 Hybrid, Electric Machine, Hybrid Powertrain

\section{Introduction}

Axial flux electric machines have been known to offer excellent power and torque densities for many years. In fact some of the very first electrical machines were of the axial type [1]. However, despite their apparent performance benefits they have yet to make a significant impact, especially in automotive applications.

This lack of impact is most likely due to the difficulty in manufacturing the stators and rotors for these machines. This manifests itself in real machines as a reduction in performance when compared with prediction or the cost of manufacturing being prohibitively high. Nevertheless in recent years various axial flux machines have entered the market, especially in applications where high torque and power are required [2, 3].

Whilst these machines are starting to gain market acceptance it has to be noted that their use is mainly in niche areas where their shape offers a specific benefit. Most often this benefit is even more pronounced if the machine is fully integrated into the powertrain.

This paper will describe the benefits and challenges of axial flux electric machines. In the first section it is argued that AF technology can 
a)

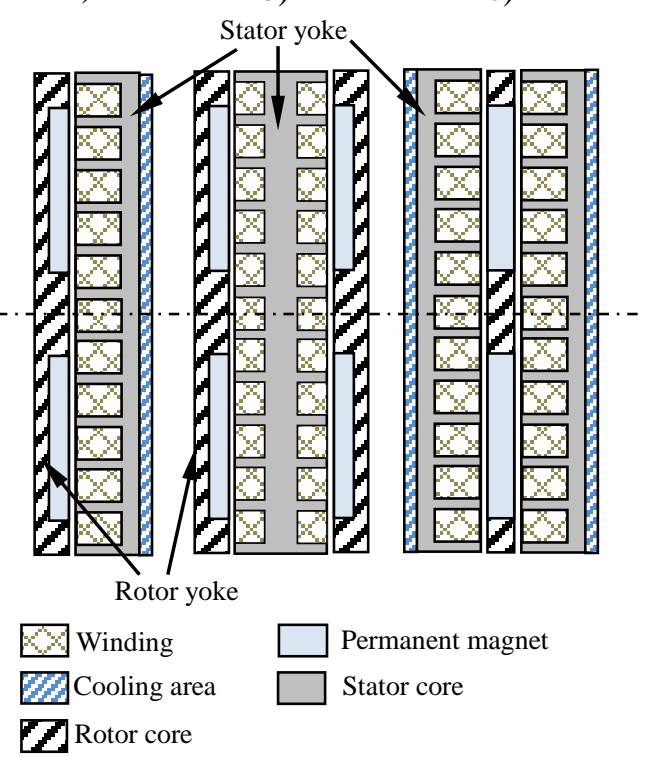

Figure 1: Three basic AFM topologies. Single sided axial flux configuration (a), central stator axial flux configuration (double rotor) (b), and central rotor axial flux configuration (double stator) (c)

offer great benefits if integrated into hybrid powertrains. The analysis techniques required will be described followed by a specific machine development for a P2 hybrid application.

\section{Types of Axial Flux Machine}

Axial flux machines come in various configurations. In all configurations the magnetic flux passes axially through the air-gap, though there are variations with respect to the mechanical and electro-magnetic designs, namely; permanent magnet (PM), interior permanent magnet, induction, brushed DC and switched reluctance machines. For the purpose of this paper only PM machines are considered although similar benefits and challenges are expected when different electromagnetic machine concepts are compared with radial designs.

\subsection{Axial flux configurations}

AF machines can be designed as single-sided, central rotor or central stator [4, 5], Figure 1. Multiple stages may also be implemented.

Single sided machines have one rotor and one stator facing each other as shown in Figure 1a [6]. These machines offer the lowest part count but given that they only have one active air-gap they also offer the lowest power. Even if the single air-gap is compensated for with higher copper-content in the winding the impact will be limited as only one stator rear face is available for cooling. A further downside is the attraction force between the rotor and the stator which can be several $\mathrm{kN}$ in magnitude.

With regards to cooling, these machines can either be air-cooled or the heat produced in the stator can be removed via indirect cooling over the backside of the stator. This enables conventional cooling using water/glycol and allows the machine to be integrated into a cooling circuit shared with other powertrain components.

Central stator machines have a single stator sandwiched between two rotors. This machine requires rotors with keeper disks (rotor yokes) acting as return paths for the magnetic flux as shown in Figure 1b [7]. These machines are commonly seen as the most compact designs and can be designed with no yoke in the stator. However in terms of practical implementation there are two major challenges. Firstly, the machine has two rotating disks at its ends with the non-rotating stator in the middle. This makes integration into a vehicle chassis more difficult. In terms of cooling for high performance machines direct liquid cooling in the stator gives the best performance [8]. Alternatively air can be circulated through the machine but this reduces the power output. Indirect cooling as in the other configuration is difficult for this configuration.

Central rotor machines have a single rotor sandwiched between two stators, as shown in Figure 1c [7]. They are effectively two single sided machines fixed together with the rotor yoke removed. The rotor can be made from magnetic or non-magnetic materials. The flux passes through the rotor and interacts over two air-gaps with the two stators. This configuration doubles the available cooling area (as there are two stator rear faces available to cool) and thus increases the power output. Another advantage is that conventional coolant can be used to cool the stators indirectly. A further benefit is that the active parts are arranged such that the non-rotating components are 'on the outside' of the machine. This eases integration into a vehicle chassis.

These various configurations have been analysed and often the central stator machine is cited as the best solution $[8,9]$.

Whilst a theoretical analysis might suggest that only one axial flux configuration offers the best solution, it is the experience of the authors that application-specific integration favours different configurations. 


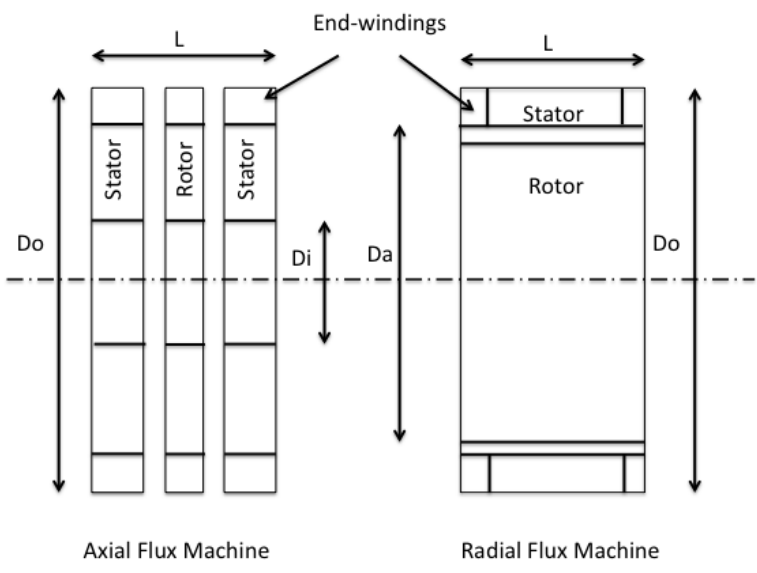

Figure 2: Schematic of radial and axial flux machine major dimensions

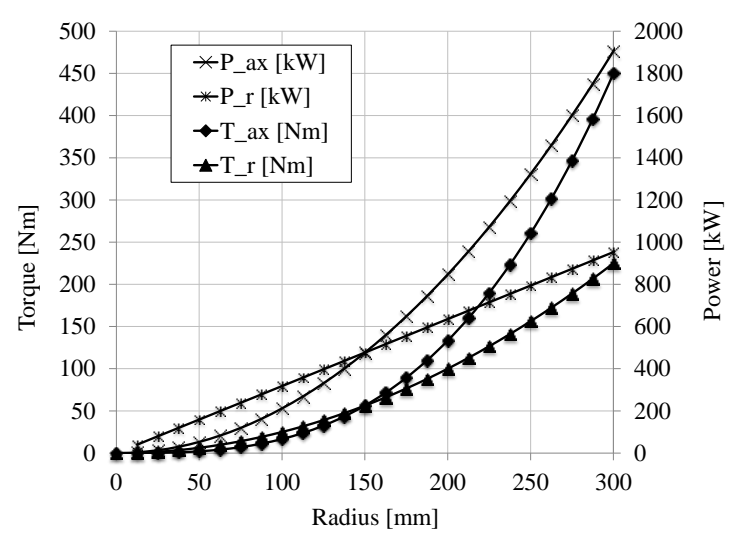

Figure 3: Effect of radius variation for radial and axial machine starting with similar performance at $150 \mathrm{~mm}$ radius. $\mathrm{P}_{-}$ax and $\mathrm{T} \_$ax are the power and torque available from an axial machine, $\mathrm{P} \_r_{-}$and $\mathrm{T}_{-} \mathrm{r}$ are the power and torque available from a radial machine

\subsection{Simple analysis of AF performance}

The performance of an electric machine in terms of its mechanical power and torque can be analysed by looking at the air-gap magnetic field and the shear stress it can create. Assuming that the magnitude of the shear stress is independent of geometry (radial/axial) then in a first approximation the integral over the air-gap multiplied by its radius gives the machine torque. Figure 2 depicts the major dimensions of an axial and radial machine. Assuming that the radial machine stator and the axial flux end-windings use up the same space then the active diameter $D_{a}$ of the radial machine is similar to the largest magnetic diameter of the axial machine.

If the electromagnetic torque is a function of the magnetic shear stress $G$ then the torque for a radial and an axial flux machine is expressed as (1) and (2), respectively. This is achieved by integrating $G$ over the air-gap area and the respective radius.

$$
\begin{aligned}
& T_{r}=\frac{D_{a}^{2} \pi L}{2} G \\
& T_{a x}=\frac{4 \pi G}{3} \frac{D_{a}^{3}-D_{i}^{3}}{8}
\end{aligned}
$$

For a given machine length it can be seen that the axial machine increases its torque to the power of three of the diameter and the radial one to the power of two.

Whilst (2) shows a drastic increase in torque with diameter the effect of the stresses in the rotor needs to be considered when choosing the diameter of machine. As the diameter increases the allowable operating speed needs to be reduced leading to a lower than to the power of 3 increase in output power.

In order to retain the magnets at high rotational speeds a retention feature e.g. banding is needed. It is worth noting that in a surface mount radial machine this intrudes into the air-gap forcing the gap to increase whilst in the axial machine it does not impact on air-gap length.

Figure 3 shows how torque and power vary when a radial and an axial machine of originally $150 \mathrm{~mm}$ radius with the same performance have their diameters varied. The power output takes into account rotor stresses and as a result the power output increases only in relation to the power of 2 to the diameter.

For any given space envelope into which a machine needs to be integrated the ratio of $L$ to $D$ will dictate which machine type will produce more torque.

It should not be forgotten that in hybrid applications there is often a need to package a clutch within the inner diameter of the machine. In a radial machine this space is not used, whereas in an axial machine it will result in an output torque reduction as can be seen in (2). More in-depth analysis by Lipo et all [10] shows that the max. specific torque is achieved when

$$
\frac{D_{o}}{D_{i}}=\sqrt{3}
$$

and therefore, depending on the torque and $D_{\mathrm{o}}$ required, clutch integration may be possible without deviating from the ideal $D_{i}$ value.

In the experience of the authors an axial machine will give a higher power output than a radial machine when (4) holds. However it is difficult to generalise as the ratio of internal to external diameter also impacts on the best solution.

$L \leq 0.7 D_{o}$ 


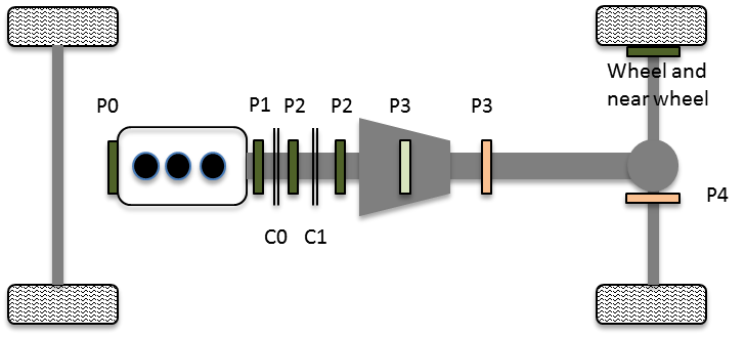

Figure 4: Possible motor (P) and coupling (C) positions in a hybrid system

\section{Machine Positions in Hybrid Applications}

The space envelope available depends on the position of the electric machine in a hybrid powertrain making some more beneficial for the application of axial flux machines. Figure 4 depicts the commonly considered machine positions. The in-line configurations of positions $\mathrm{P} 0, \mathrm{P} 1$ and $\mathrm{P} 2$ commonly require a machine that is short and hence are candidates for axial flux technology integration.

An additional benefit of the central rotor machine in the P2 position is that cold plates at each stator rear face act as thermal barriers and can isolate the electric machine from the heat produced by the engine.

The benefits of axial flux in P3 are less clear and depend on the specifics of the integration. If the integration is within the gearbox an AF machine may offer a benefit. The same applies to P4 electric axles where the type of integration most often requires long thin and hence radial type machines. However, high power density applications and those where the motor and gearbox outputs are coaxial may favour $\mathrm{AF}$ technology. For integration of a machine near or in the wheel AF technology is very attractive [11].

\section{Manufacturing Options and Design Aspects}

The main reason for the slow uptake of the axial flux technology is the lack of suitable materials and manufacturing processes. The disk like shape of the stator poses a major challenge for production. With the advances in soft magnetic composites (SMC) it has become possible to design stators built from sintered SMC segments [8], alternatively a coil of electric steel with stamped slots can be used [13]. Both options offer different benefits and challenges. The relatively high permeability of electric steel offers superior flux carrying capacity over SMC stators. However the forming of the stator core requires complex machinery and can be slow. SMC cores have the potential for high volume automated manufacturing. In terms of performance the benefit of SMC is that it incurs lower losses at high frequencies and carries flux equally well in all three dimensions. These characteristics must be harnessed in order to deliver good results.

\section{Design Methodology}

GKN EVO uses a range of design tools during the development of bespoke machines. These include both proprietary analytical models and commercially available FEA codes.

\subsection{Analytical modelling}

Whilst the analysis described in 2.2 was based on a fixed magnetic shear stress, in order to predict actual machine performance, the analytical model presented by [12] is used in this work to perform machine design studies. It is quick to solve, allowing many machine variants to be compared in a short amount of time. The model uses a multiphysics lumped parameter circuital approach, producing predictions of machine performance by solving coupled electromagnetic, electrical, and thermal circuits. The model takes into account inverter switching strategy, DC voltage levels and environmental conditions. It also allows different winding arrangements, pole numbers, active diameters, lengths, slot geometry, fill factors etc., to be investigated.

\subsection{D FE modelling}

The analytical tool is very effective for calculating machines within the calibrated technology range. In order to investigate new machine concepts, and to perform the detailed design of existing concepts, $3 \mathrm{D}$ finite element analysis is required. This is especially useful for the calculation of losses in the rotor and the stator, as well as for quantifying important phenomena such as saturation, proximity and skin effects [14] etc.

Heat transfer and computational fluid dynamic (CFD) models are also constructed to predict the temperature of machine components $[15,16]$.

\section{Case Study: E Segment Car P2 Hybrid Module Machine}

This section presents a case study to demonstrate the potential of AF machines for use in $\mathrm{E}$ segment P2 hybrids. The machine operates in line with the engine and therefore its speed range is defined by it. Starting the engine from cold whilst driving in electric mode defines the peak torque requirement. 
Table 1: $\mathrm{P} 2$ machine parameters

\begin{tabular}{|l|c|l|}
\hline DC Voltage & $280-380$ & $\mathrm{~V}_{\text {DC }}$ \\
\hline $\mathrm{I}_{\max }$ & 500 & $\mathrm{~A}_{\mathrm{rms}}$ \\
\hline $\mathrm{n}_{\max }$ & 7000 & $\mathrm{rpm}$ \\
\hline $\mathrm{n}_{\text {nom }}$ & 2800 & $\mathrm{rpm}$ \\
\hline $\mathrm{T}_{\text {nom }}$ & 90 & $\mathrm{Nm}$ \\
\hline $\mathrm{T}_{\max }(20 \mathrm{~s})$ & 240 & $\mathrm{Nm}$ \\
\hline $\mathrm{T}_{\max }(5 \mathrm{~s})$ & 350 & $\mathrm{Nm}$ \\
\hline Casing Dia. & 290 & $\mathrm{~mm}$ \\
\hline Active Dia. & 235 & $\mathrm{~mm}$ \\
\hline Length inc. casing & 80 & $\mathrm{~mm}$ \\
\hline Active length & 58 & $\mathrm{~mm}$ \\
\hline Water cooled (55 C) & 8 & $1 / \mathrm{min}$ \\
\hline
\end{tabular}

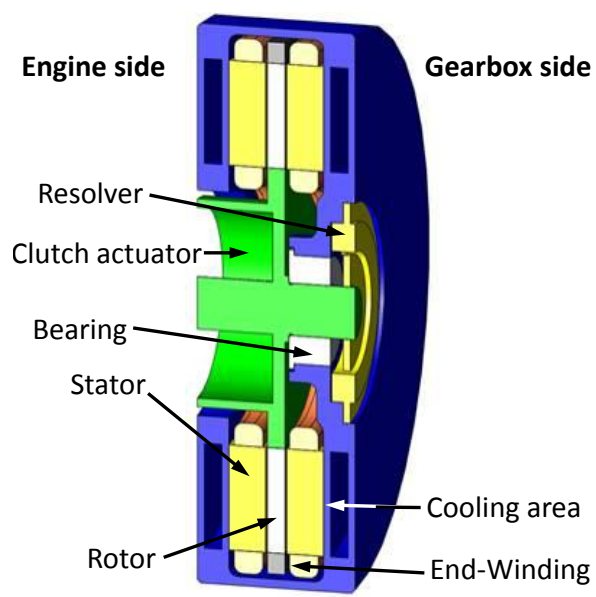

Figure 5: CAD model of integrated electric machine

a)

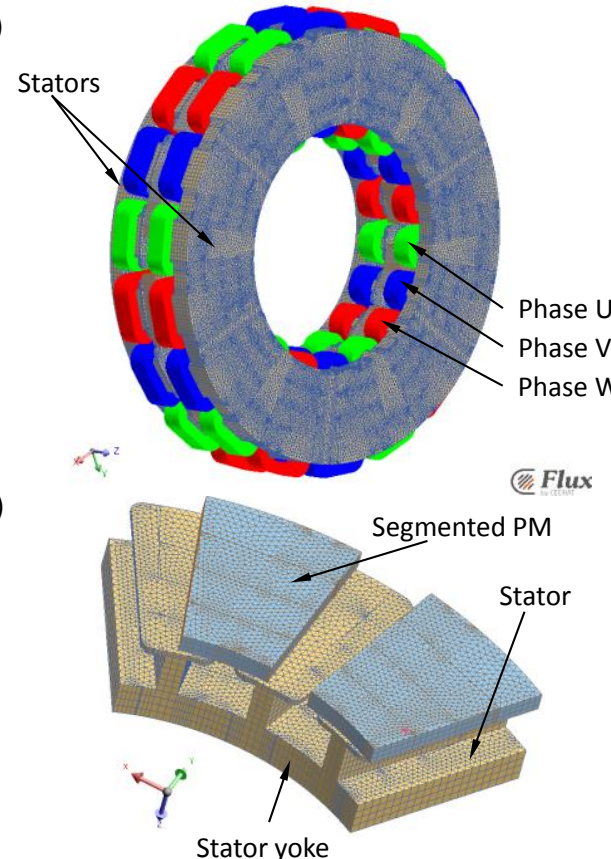

Figure 6: Outline of the whole FE model with mesh descritization (a) and the model with symmetry (b)

\subsection{Prototype motor construction}

A machine required to be placed in between the clutch and engine was designed with the additional requirement of placing the clutch and actuator in the middle of the machine. The machine chassis needs to be designed such that it facilitates the cooling of the motor and allows integration of the machine into the powertrain as shown in Figure 5. The main performance and size parameters are shown in Table 1.

The AF motor is a three-phase PM motor that uses proprietary axial flux technology to deliver very high torque and power density in a compact and lightweight unit. The disk shape of the motor makes it particularly beneficial in this application as there is limited space available. The AF topology considered here is of the single rotor, double stator variety.

A P2 electrical machine is directly connected to the vehicle transmission and rotates when the vehicle is moving. In this case of PMSM, the electrical machine must be field-weakened to control its back electromotive force whenever the transmission input speed exceeds its base speed [12].

\subsection{Performance prediction}

The analytical analysis tool [12] was used to investigate the application defined in Table 1. A parametric study was performed and based on its outcome an FEA optimisation was run to ensure losses were modelled correctly. FEA analysis was used to verify the predicted performance from the analytic model and to optimise the machine design. Since the prototype motor considered is of the axial flux topology 3D FEA was used to ensure accurate electromagnetic analysis, Figure 6.

At this stage of the performance investigation a four-segmented PM array is considered. Figure 6 shows the mathematical model of the axial flux PM motor with a winding sequence $\mathrm{U}+/ \mathrm{V}+/ \mathrm{W}+$. Due to rotational symmetry and XY-plane symmetry only the $1 / 12$ section of the complete motor cross-section needs to be modelled Figure $6 b$.

The power loss associated with the PM rotor assembly is important as excessive rotor temperature may result in premature failure [1719]. Cooling of a central rotor is challenging and hence the reduction of losses in the magnets is paramount. It is obvious that high rotor temperature leads to a reduction in the torque and can be the cause of irreversible demagnetization of the PM array. The temperature of the PM array has a significant influence on the loss predictions. This 


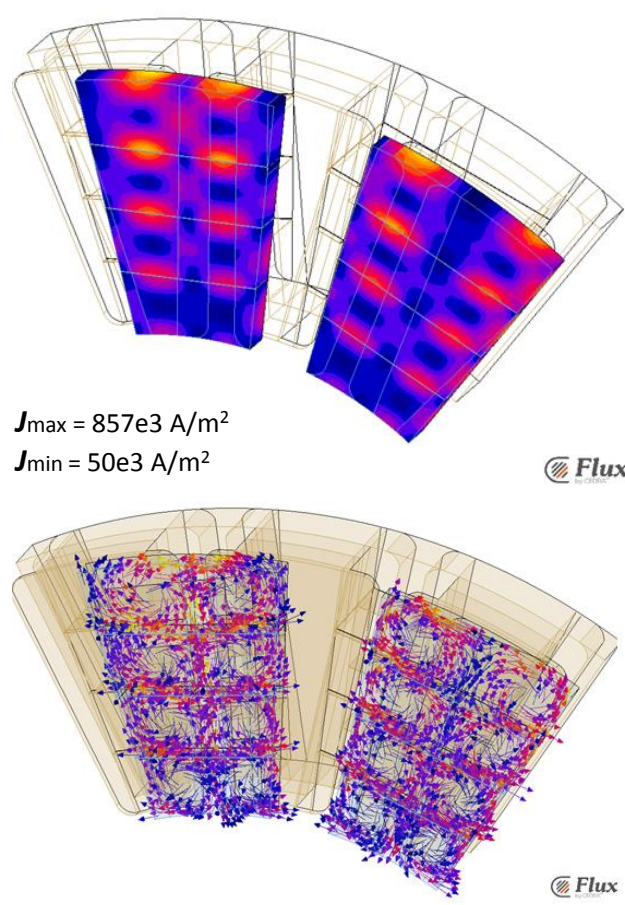

Figure 7: Calculated PM eddy current loss distribution at open-circuit operation (1000rpm)

is because the electrical conductivity of PM material is temperature dependant.

The previously described FEA model has been employed to predict the induced eddy-current losses. These losses are induced by permeance variations caused by stator slotting and from the armature reaction field [20-25]. The armature reaction is caused by the higher order spatial harmonics of the winding distribution. In the present work, the phase current is assumed to be sinusoidal. Figure 7 shows the results of the magnet eddy-current distributions at open-circuit operation when the rotational speed is 1000rpm.

In this analysis the PM array was assumed to have a fixed, uniform temperature of $25^{\circ} \mathrm{C}$. The magnet loss was computed as in (5). Where $\mathbf{E}$ is the electric field strength, $\mathbf{J}$ is the current density within the PM and $\rho$ is the resistivity of the PM $\left(1.6 \cdot 10^{-6} \Omega \cdot \mathrm{m}\right)$.

$$
P_{P M}=\iiint_{V} \mathbf{E} \cdot \mathbf{J} d V=\rho \iiint_{V} \mathbf{J}^{2} d V
$$

\subsection{Comparison between predicted and measured results}

The test arrangement is shown in Figure 8. The shaft of the prototype motor is directly coupled to a dynamometer load machine. The test motor is supplied with coolant from a temperature controlled source.

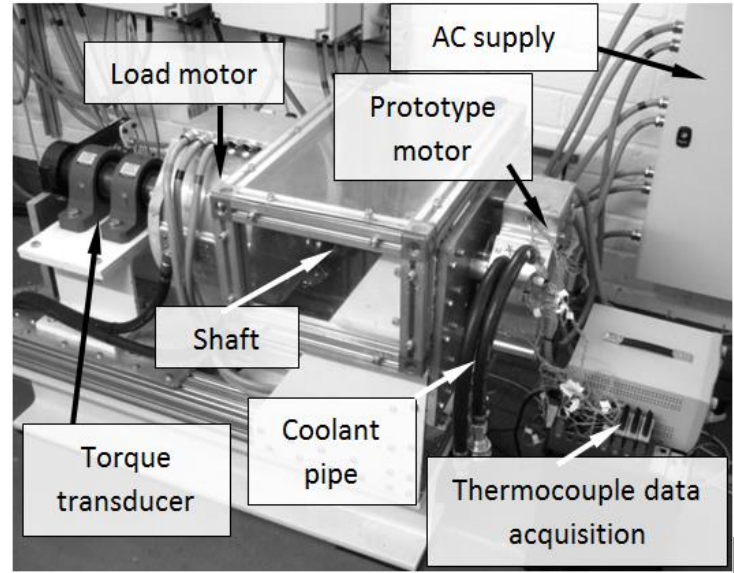

Figure 8: Prototype AF machine on test

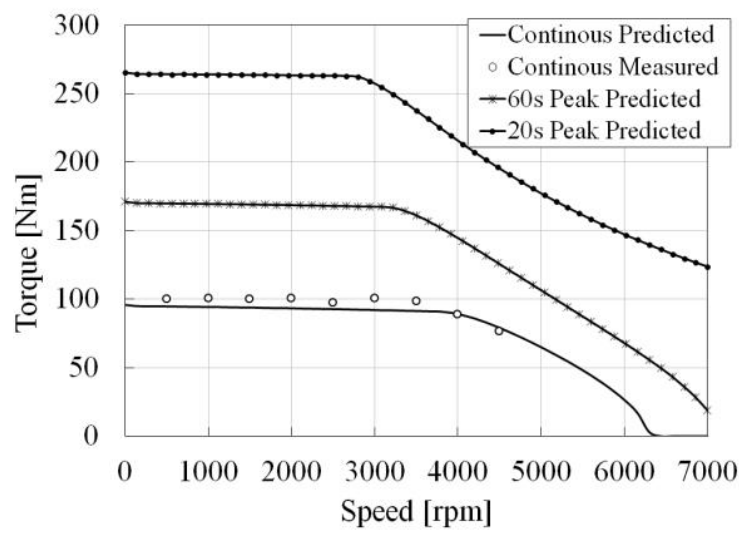

Figure 9: Analytical versus measured performance of the prototype at $320 \mathrm{Vdc}$

Temperatures are measured at various positions in the stator in order to ensure that hotspots can be captured.

Figure 9 presents a comparison between measured and predicted continuous torque of the prototype machine. The agreement is good, validating the models used for performance prediction.

Table 2 shows the predicted and measured machine parameters including winding resistance $\left(\mathrm{R}_{\text {wind }}\right)$, nominal torque $\left(\mathrm{T}_{\text {nom }}\right)$, short-circuit current $\left(\mathrm{I}_{\text {short }}\right)$, torque constant $(\mathrm{Kt})$, voltage constant $(\mathrm{Ke})$, and cogging torque $\left(\mathrm{T}_{\mathrm{cog}}\right)$. Again, the agreement between the predicted and measured values is good.

The most common electric drive faults can be categorized as: mechanical failures, control failures, and electrical failures. Electrical failures commonly manifest themselves as inverter failures and winding short circuits. Short-circuit events may have a serious impact on traction motors and/or vehicle stability.

Figure 10 shows a comparison between predicted and measured short-circuit performance of the prototype motor. The figure shows that when the 
Table 2: Comparison of Measured / FEA / Analytical machine parameters

\begin{tabular}{|l|c|c|c|}
\hline \multirow{2}{*}{ Parameter } & \multirow{2}{*}{ Measured } & \multicolumn{2}{|c|}{ Predicted } \\
\cline { 3 - 4 } & & Analytical & FEA \\
\hline $\mathrm{R}_{\text {wind }}[\Omega]$ & 0.055 & 0.054 & $\mathrm{n} / \mathrm{a}$ \\
\hline $\mathrm{T}_{\text {nom }}[\mathrm{Nm}]$ & 103 & 98 & 107 \\
\hline $\mathrm{I}_{\text {short }}\left[\mathrm{A}_{\mathrm{rms}}\right]$ & 302 & 304 & 306 \\
\hline $\mathrm{Kt}\left[\mathrm{Nm} / \mathrm{A}_{\mathrm{rms}}\right]$ & 0.92 & 0.95 & 0.95 \\
\hline $\mathrm{Ke}[\mathrm{V} \cdot \mathrm{s} / \mathrm{rad}]$ & 0.53 & 0.58 & 0.54 \\
\hline $\mathrm{T}_{\text {cog }}[\mathrm{Nm}]$ & 8 & $\mathrm{n} / \mathrm{a}$ & 7.5 \\
\hline
\end{tabular}

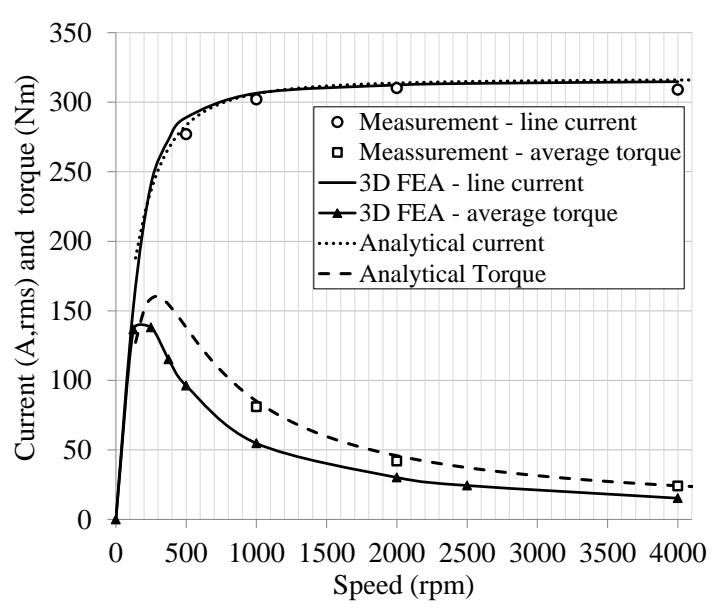

Figure 10: Comparison of short-circuit behaviour measured/analytical/FEA

Table 3: Sample of GKN EVO central rotor motor range

\begin{tabular}{|l|l|l|l|l|l|}
\hline Active $\varnothing[\mathrm{mm}]$ & 360 & 305 & 280 & 235 & 235 \\
\hline Active $\mathrm{L}[\mathrm{mm}]$ & 74 & 59 & 72 & 70 & 58 \\
\hline M total $[\mathrm{kg}]$ & 40 & $\mathrm{n} / \mathrm{a}^{*}$ & 31 & 24 & $\mathrm{n} / \mathrm{a}^{*}$ \\
\hline $\mathrm{M}$ active $[\mathrm{Kg}]$ & 24.2 & 15.8 & 16.8 & 12.4 & 9.8 \\
\hline $\mathrm{n}_{\max }[\mathrm{krpm}]$ & 5 & 7.5 & 8 & 12 & 6.5 \\
\hline $\mathrm{T}$ cont. $[\mathrm{Nm}]$ & 250 & 155 & 145 & 100 & 97 \\
\hline $\mathrm{T}_{\max }(20 \mathrm{~s})[\mathrm{Nm}]$ & 660 & 310 & 350 & 250 & 240 \\
\hline
\end{tabular}

*Part of the Powertrain

machine operates at speeds greater than 250rpm the torque rapidly decreases. A $160 \mathrm{Nm}$ peak value of short-circuit torque can be seen at 250rpm (measured value).

\section{Conclusions}

The application of AF technology to hybrid powertrains can offer a significant torque and power increase over conventional technologies. Better understanding of the design and manufacturing process make these machines feasible.

Table 3 shows examples of machines developed by GKN EVO. The machines with active $\varnothing 305$ and $235 \mathrm{~mm}$ have been specifically developed for integration into hybrid powertrains in the P2 position.

\section{References}

[1] N. Tesla, Notes on a unipolar dynamo, The Electrical Engineer, NY, 1891.

[2] F. Profumo, Zheng Zhang; A. Tenconi, Axial flux machines drives: a new viable solution for electric cars, IEEE Transactions on Industrial Electronics, 44/1(1997), 39-45.

[3] M. Aydin, S. Huang, T.A. Lipo, Axial flux permanent magnet disc machines: a review, Wisconsin Electric Machines \& Power Electronics Consortium, University of Wisconsin-Madison, Madison, WI 53706-1691, 2004.

[4] A. Parviainen, M. Niemela, J. Pyrhonen, A novel axial flux permanent magnet machine to laboratory use, $11^{\text {th }}$ International Symposium on Computer Engineering in Applied Electromagnetism, 2005, 333-336

[5] S.O. Ani, Human powered axial flux permanent magnet machines: Review and comparison, Energy Conversion Congress and Exposition (ECCE), 2010, 4165-4170.

[6] X. Yang, D. Patterson, J. Hudgins, Core loss measurement in a fabricated stator of a singlesided axial flux permanent magnet machine, Electric Machines \& Drives Conference (IEMDC), 2013, 612-617.

[7] A. Mahmoudi, H.W. Ping, N. A. Rahim, A comparison between the TORUS and AFIR axialflux permanent-magnet machine using finite element analysis, IEEE International Electric Machines \& Drives Conference (IEMDC), 2011, 242-247.

[8] T.J. Woolmer, M.D. Mcculloch, Analysis of the yokeless and segmented armature machine, IEEE International Electric Machines \& Drives Conference, (IEMDC), 2007, 704-708.

[9] H.Surong, J. Luo, F. Leonardii, T.A. Lipo $A$ comparison of power density for axial flux machines based on general purpose sizing equations, IEEE Transactions on Energy Conversion, 2(1999), 185-192.

[10] Aydin, M., Surong Huang; Lipo, T.A. Lipo, A new axial flux surface mounted permanent magnet machine capable of field control, $37^{\text {th }}$ Industry Applications Conference, 2002, 1250-1257.

[11] A.P. Rodríguez, I.I. Aguinaga, Eunice Project: Eco-design and Validation of In-Wheel Concept for Electric Vehicles.

[12] A.C. Malloy, A. Mlot, M.J. Cordner, M. Lamperth, Axial flux machines for hybrid module applications, IEEE International Electric Vehicle Conference, 2014.

[13] P. Anpalahan, M. Lamperth, Design of multi-stack axial flux permanent magnet generator for a hybrid electric vehicle, IEEE International Vehicle 
Power and Propulsion Conference (VPPC), 2006, 1-4.

[14] R. Wrobel, A. Mlot, P. H. Mellor, Contribution of end-winding proximity losses to temperature variation in electromagnetic devices, IEEE Transactions on Industrial Applications, 59/2(2012), 848-857.

[15] J. Hey, A. C. Malloy, R. F. Martinez-Botas, M. Lamperth, Experimentally determined thermal parameters of an energy conversion device using a constraint least square parameter estimation method coupled with an analytical thermal model, Proceedings of the $15^{\text {th }}$ International Heat Transfer Conference, 2014.

[16] J. Hey, A. C. Malloy, R. F. Martinez-Botas, M. Lamperth, Conjugate heat transfer analysis of an energy conversion device with an updated numerical model obtained through inverse identification, Energy Conversion and Management, 94 (2015), 198-209.

[17] A.C. Malloy, R.F. Martinez-Botas, M. Jaensch, M. Lamperth, Measurements of heat generation rate in permanent magnet rotating electrical machines, $6^{\text {th }}$ IET International Conference on Power Electronics, Machines and Drives (PEMD), 2012, 1-6.

[18] D.A. Howey, A.S. Holmes, K.R. Pullen, Measurement and CFD prediction of heat transfer in air-cooled disk-type electrical machines, IEEE Transactions on Industrial Applications, 47/4 (2011), 1716-1723.

[19] A. C. Malloy, R. F. Martinez-Botas, M. Lamperth, Measurement of magnet losses in a surface mount permanent magnet synchronous machine, IEEE Transactions on Energy Conversion, 30/1(2015), 323-330.

[20] F. Caricchi, F. Crescimbini, L. Solero Capponi, Experimental study on reducing cogging torque and core power loss in axial-flux permanentmagnet machines with slotted winding, $37^{\text {th }}$ IEEE Annual Industry Applications Conference, 2(2002), 1295-1302.

[21] N. Schofield, K. Ng, Z. Q. Zhu, D. Howe, Parasitic rotor losses in a brushless permanent magnet traction machine, IEEE International conference on Electrical Machine and Drives, (IEMDC), 1997, 200-204.

[22] H. Polinder, M. J. Hoeijmakers, Eddy-current losses in the permanent magnets of a PM machines, IEEE International Conference on Electrical Machines and Drives, (IEMDC), 1997, 138-142.

[23] H. Polinder, M.J. Hoeijmakers, Eddy-current losses in the segmented surface-mounted magnets of a PM machine, IEE Proceedings Electric Power Applications, 146/3 (1999), 261266.
[24] K. Atallah, D. Howe, P.H. Mellor, D. A. Stone, Rotor loss in permanent-magnet brushless AC machines, IEEE Transactions on Industrial Applications, 36/6 (2000), 1612-1618.

[25] K. Yamazaki, Y. Fukushima, M. Sato, Loss analysis of permanent-magnet motors with concentrated windings - variation of magnet eddycurrent loss due to stator and rotor shapes, IEEE Transactions on Industrial Applications, 45/4 (2009), 1334-1342.

\section{Authors}

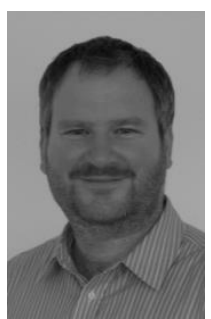

Michael U. Lampérth graduated from Winterthur Polytechnic, Switzerland, in 1989 and received the $\mathrm{PhD}$ from Imperial College in 1999, where he was a lecturer until 2010. He was founder and CTO of Imperial College spin-out company EVO-Electric, which was formed to commercialize innovative axial flux electrical motors and generators. He is currently CTO of GKN-EVO eDrive Systems Ltd., Woking, UK and involved in collaborative R\&D programs between Industry and Universities in the area of electric motors and hybrid systems.

Adam C. Malloy received the B.Sc. (Hons.) degree in Industrial Design and Technology from Loughborough

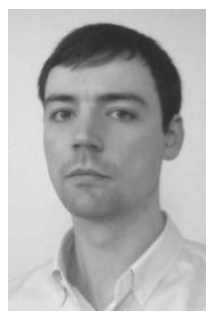
University, Loughborough, U.K., in 2007. He received the Ph.D. degree from Imperial College London, London, U.K, in 2014. He currently works at GKN-EVO eDrive Systems Ltd., Woking, UK where his research interests include the multiphysics analysis of electrical machines.

Adrian Mlot received the M.Sc.Eng. and $\mathrm{Ph} . \mathrm{D}$ degrees from the Technical University of Opole, Poland, in 2003 and 2007, respectively. In 2003, he became an Assistant with the Technical University of Opole. In 2008, he joined and became a Research Assistant with the University of Bristol, UK. Since 2013 he has been employed in GKN-EVO eDrive Systems Ltd., Woking, UK. as a motor design engineer.

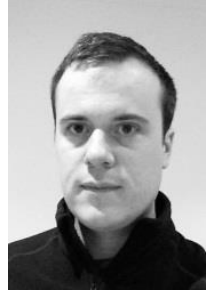

Mark Cordner received the M.Eng. degree in Mechanical Engineering from Imperial College London, U.K., in 2009. He currently works at GKNEVO eDrive Systems Ltd., Woking, UK where he leads the Hybrid and Integration team. 